\title{
Nurturing constructive change that works: a critical theory-informed model for transforming health service psychologists' views of people with disabilities
}

\author{
Roy O. Gathercoal, ${ }^{1}$ Kathleen A. Gathercoal, ${ }^{2}$ Winston Seegobin, ${ }^{2}$ Sarah Hadley ${ }^{1}$ \\ ${ }^{1}$ Independent scholar; ${ }^{2}$ Graduate Department of Clinical Psychology, George Fox University, Newberg, OR, USA
}

\begin{abstract}
We have been developing and refining a disability training exercise for health service psychologists that is ever more effective at encouraging lasting change in the way students regard disabilities and the people who live with those disabilities. Although research suggests that simulation exercises tend to be ineffective at creating long-term attitude change in participants, quantitative and qualitative results indicate our exercise, composed of a simulation followed by debriefing and reflection, helps professionals better understand some of the challenges people with disabilities daily face, and how those challenges can affect their well being. We found this combination is more likely to yield long-term changes than any of these approaches alone. This paper is not principally the description of a pedagogical technique, but instead is an examination of how the combination of simulation, debriefing, and reflective journaling may challenge taken-for-granted assumptions about disabilities, e.g., that disabilities transform individuals into a different kind of human being (with either superhuman powers or as object of pity) instead of seeing these individuals as ordinary people facing extraordinary, and often society-created obstacles. One frequent call of Critical Theorists is to challenge those things we take for granted. Social and cultural structures create specific viewpoints and thus problematizing the apparent is necessary for understanding of, and emancipation from, potentially oppressive social structures. Inspired by this call to render the taken-for-granted as problematic, the exercise we describe creates inversions of performer/audience, professional/student, and scientist/researcher positions. In each of these inversions, the role of the objective observer is denied and the student is invited to engage in his or her own evaluative and potentially transformative experience. Through each of these inversions, different realities can be more readily utilized by thoughtful students to render problematic some of the dom-

Correspondence: Roy O. Gathercoal, 2504 Haworth Avenue, Newberg, OR 97132, USA.

Tel: +1.503.537.1162.

E-mail: rgathercoal@frontier.com

Key words: Disability; Health service psychology; Attitude change; Critical theory; Pedagogy.

Contributions: ROG made substantial contributions to planning inant views about people with disabilities. To make this case, we utilize both qualitative and quantitative methods. The students' own words, captured in their journals before and after the exercise, are examined in comparison with program goals and features. The weight of the evidence is impressive, indicating that the combination of simulation, debriefing and journaling reflection are effective at creating a space in which change of attitudes does occur.
\end{abstract} and executing the pedagogical intervention, data collection, drafting and revising the article, and approving the final version to be published; KAG made substantial contributions to planning and executing the pedagogical intervention, data analysis and interpretation, drafting and revising the article, and approving the final version to be published; WS made substantial contributions to planning and executing the pedagogical intervention, data collection and interpretation, drafting the article, and approving the final version to be published; SH made substantial contributions to data analysis and interpretation, conceptualizing the article, and approving the final version to be published.

Conflict of interest: the authors declare no potential conflict of interest.

Received for publication: 15 November 2016.

Revision received: 9 January 2017.

Accepted for publication: 11 January 2017.

This work is licensed under a Creative Commons Attribution NonCommercial 4.0 License (CC BY-NC 4.0).

(C) Copyright R.O. Gathercoal et al., 2017

Licensee PAGEPress, Italy

Qualitative Research in Medicine \& Healthcare 2017; 1:29-38

doi:10.4081/qrmh.2017.6391

\section{Introduction}

The need for improved health care for people with disabilities has been recognized both nationally and internationally. There is ample evidence of health care disparities experienced by people with disabilities,,$^{1,2}$ making them the largest under-served group in the United States and, by some estimates, including close to one-in-five Americans. ${ }^{3-5}$ Health authorities, including the US Surgeon General, the World Health Organization, The United Nations, and the World Bank, have called for improvements. For example, one of the public health goals of the United States for people with disabilities, stated in Healthy People 2020, is reducing barriers to participating in community activities and within health care settings. ${ }^{4}$ But in 2005 , the Surgeon General pointedly identified the attitudes of health care providers as a critical barrier to the health care of people with disabil- 
ities. ${ }^{6}$ According to Kirschner and Curry, The failure of medical education programs to teach concepts of disability was identified as a root cause, and educators were encouraged to increase knowledge among health care professionals and provide them with tools to screen, diagnose, and treat the whole person with a disability with dignity'. ${ }^{7}$

As noted in the American Psychological Association's Guidelines for Assessment of and Intervention with Persons with Disabilities, psychologists are uniquely positioned to help individuals with disabilities become self-determining citizens of our diverse society. ${ }^{8}$ However, few psychologists receive formal or informal training about disabilities. Vogel, McMinn, Peterson and Gathercoal surveyed students, interns, faculty, and training directors at APA-accredited doctoral programs and pre-doctoral internships for health service psychologists regarding the adequacy of diversity training, including disabilities, within their programs. Results indicated a clear hierarchy in coverage of topics with least attention given to the dimensions of diversity pertaining to disabilities, age, religion, and spirituality. ${ }^{9}$ Recent curriculum reviews indicate there are fewer courses, both in the undergraduate and the graduate psychology curriculum, about disabilities and fewer courses in which disabilities are covered in depth than in the past. ${ }^{10,11}$ Andrews and Lund estimate that only between 3 and $8 \%$ of health service psychologists are people with disabilities ${ }^{12}$ and as a result, few psychologists learn about disabilities informally by observing peers or mentors who have disabilities. So the challenge to develop or discover better ways of helping our students to be more effective health care professionals serving people with disabilities continues.

Shakespeare and Kleine (2015) recently summarized the pedagogical approaches in 48 professional papers that described and assessed teaching interventions to improve health care providers' knowledge and attitudes regarding people with disabilities. ${ }^{13}$ They created a taxonomy based on the pedagogical delivery method and linked those with outcomes such as attitude change, increased knowledge, and improved comfort and communication with people with disabilities. Specifically, they reported that Traditional Lectures (33 papers) were relatively ineffective; Encounters with Standardized Patients (23 papers) had more impact on knowledge and attitudes than lecture alone; Visits to community facilities serving people with disabilities (9 papers) led to improved interactions with people with disabilities; Simulations (4 papers) may have lead to distorted understandings of people with disabilities e.g. feelings of pity; Interacting with people with disabilities or their family members ( 15 papers) was memorable and led to improved attitudes; Caring for a person with disabilities e.g. for several weeks in a clinical setting (9 papers) was very effective in changing attitudes and the change was generalizable. Shakespeare and Kleine concluded, Across the studies, the most positive evaluations were of opportunities to meet disabled or older people, associated with positive change in attitudes. ${ }^{13}$

Our collaborative work with people with disabilities has evolved over the past ten years. In 2006, KG, a faculty member in a Graduate Department of Clinical Psychology, and RG, her husband, an Organization Communications scholar and a person with a disability, developed a disability simulation and didactic debriefing exercise for first-year graduate students in a Lifespan Development course. As KG's course load changed and WS joined the faculty, the exercise moved from Lifespan Development to Multicultural Psychotherapy, a secondyear course. WS and RG continued to offer the exercise, modifying it to increase the time and emphasis on the didactic debriefing and adding reflective journaling.

Through these changes we have witnessed the improving effectiveness of the presentation so this simulation, with debriefing presentation and reflective journaling together, is more effective at encouraging these health service psychologists to take positive, lifelong steps to make themselves more effective advocates and helpers of people with disabilities than in previous years, and the combination of the elements are more effective than any of the components alone.

Critical Theory is usually identified as encompassing the various themes, practices and trajectories identified in or developed from the propositions of the Frankfurt Institute for Social Research from about 1930 through the present. ${ }^{14}$ Whatever the focus of a particular approach to Critical Theory, at the heart is the idea that things we take for granted can be viewed in different ways, and that this process of problematizing the apparent is necessary for emancipation from potentially oppressive social structures or cultural trends and artifacts. ${ }^{15}$

Inspired by Critical Theory's frequent call to render the taken-for-granted as problematic, the exercise creates inversions of performer/audience, professional/ student and scientist/researcher positions. In each of these inversions, the role of the objective observer is denied and the student is invited to engage in his or her own evaluative and potentially transformative experience. Thus through each of these inversions, different realities can be more readily seen and utilized by thoughtful students to render problematic some of the dominant societal views about people with disabilities.

During the simulation part of the exercise, students perform routine tasks of the sort they perform many times each day, e.g., placing an order at the student cafeteria; finding a book at the library; attending a lecture in a university classroom; and using the toilet facilities in the academic buildings; as well as moving from one task to the next. Although all of the tasks are quite mundane, completing them is of course a set-up. As a person with 
a mobility disability, RG knows how difficult these ordinary tasks can be; these tasks are selected to highlight both some that cannot be completed due to architectural barriers and some which are much easier than they otherwise might be because of well-designed and maintained facilities. In the cases in which the tasks cannot be completed without outside help (fellow group members are not allowed to assist one another), students face the same kind of ambiguity faced by people with disabilities every day. They find themselves asking, Do we ask for help from these strangers? Whom do we ask? What do we think they think of us for intruding into their lives with our request?

This experience of the ordinary as novel and the typically-mundane task as overwhelming is intended to temporarily alienate the students from what would otherwise be their ordinary daily experiences. Critical theory would suggest it is this inversion of their ordinary daily experience that proves so powerful in the simulation component. Instead of engaging in races, contests or uniquely constructed complex tasks highlighting the novelty of using assistive technology, as is the case in some other simulations, students are asked to do the sorts of things they would otherwise do, mundane takenfor-granted student tasks. As a result, students perceive more clearly how challenging it would be to live ordinary life with a disability and the extent to which assistive technology can fail to compensate for the disability.

Immediately following this heightened emotional experience of feeling anxious and helpless and dealing with new ambiguity, the students enter the debriefing phase of the exercise and are presented with someone who does indeed navigate each business day in a wheelchair. Now the person with the disability is the expert. $\mathrm{He}$ is the person with the valuable experience, rather than a client needing the help of able-bodied, charitable others. The person with the disability is transformed from an objectified other, someone to be watched or studied as they attempt to live, to a model and expert encompassing many of the attributes to which these students aspire: a deep base of personal experience with exactly the types of challenges these students have just experienced and credentialed professional status. This inversion, critical theory suggests, sets the stage for an entirely different conception of people with disabilities by rendering problematic a commonly held view, one based on respect and professional expectation rather than expectation of incompetence.

An additional inversion happens as a result of the switching of the roles of professional/amateur, performer/audience, and scientist/researcher subject in the debriefing phase. The presenting individual is not a visitor to the professional world which these students represent, but is a credentialed professional, a teacher and resource, a certified member of the professional world. There is no place for pity, and thus no immediate outlet for the heightened emotional states just experienced as a result of the simulation. This is regular ordinary life the students are told, not something extraordinary. Thus the locus of the inquiry shifts subtly to being about the student's individual measuring up to the requirements of being a professional as a person with disability. Instead of assuming the role as either a novelty super hero or as a pitied victim the presentation places the student in the easily assumable role of student/professional-to-be going about ordinary life. To some extent, the student takes on the role of the disabled professional.

The focus of the debriefing then creates another inversion as the student's move from being a person experiencing a simulation to being a professional tasked with being an effective health service provider for people with disabilities. The life-task facing each student is not to complete these mundane tasks with limited capabilities, but is rather to be an effective helper to others faced with their own (possibly unknown) tasks.

Part of this transformation is accomplished through RG's discussion with the students of life-with-disability as a paradox, such that: i) the person with a disability is human and like other humans in every way except for the disability, yet ii) the disability is a limiter of full participation in society and affects every part of who that individual becomes as they live their lives. The disability simultaneously is not seen as affecting the person's basic humanity, for as participants the students retained their humanity and life context, and yet the disability affects every part of their experience of being human.

In the reflection phase of the experience, the focus turns away from describing the challenges faced by people with disabilities to discussing and journaling about how will you be effective at your profession when your client is a person with a disability? The roles of scientist/discoverer and research subject invert from one in which the students are the ones observing a life with novel disability to one in which they find themselves questioning their own readiness to be effective health care professionals - the course of study to which they are already fully committed. The subject of this exercise of inquiry shifts from being the person over there who is different from everyone else to being the students themselves, as they contemplate their coming responsibilities to be effective health care providers.

In each of these inversions the role of the objective observer is denied and the student is invited to engage in his or her own evaluative and potentially transformative experience as a collectively created and defined subject. Given the heightened emotional experience of limited success in navigating a Through the Looking glass world in which the ordinary is rendered strange and that which has always been assumed is now questioned, students are invited into the intellectual/relational experience of seeing the person with disabilities not as an un-empowered object of observation and pity, but 
rather as someone who holds the desirable position as recognized, credentialed professional and teacher.

Over the years of revising and refining this exercise, these inversions have been useful both in challenging the attitudes of students and as well as recruiting young allies in the long struggle to (re)create an accepted productive place for people with disabilities as human beings within the normal variance of human experience and capabilities rather than as others. This is the larger battle and it cannot be won without effective advocates willing to put their professional credentials behind their assertions that people with disabilities are in fact people to be seen holistically and treated with respect.

There is in this awareness of action no contamination of the research findings, for the students are never passive objects being studied by objective observers; they are always co-constituted subjects facing challenges to their previous world views together, guided by the researchers. This might be regarded as a complication in a strictly quantitative study; qualitative sensibilities call for this recognition that subjects and objects are not in fact, different things.

\section{Materials and Methods}

As creators and nurturers of this teaching/discovery tool, we wrestled with how to best assess (/confirm) its effectiveness and to communicate with others the ways in which it had been particularly effective. Looking at the project as research, with the students in roles both as scientist/investigators and as subjects, offered great promise.

Our main focus, however, is not to collect data to describe static objects in past events, but to continue the ongoing process of nurturing the evolution of this presentation so that future students/professionals will be enticed to view themselves as different subjects through this combination of a window into one familiar-yet-strange subject with prompts to re-see what is familiar with different eyes because of a new formational experience.

By utilizing methods from both qualitative and quantitative perspectives we hoped to gain a richer read or different, perhaps competing accounts, or to see different subjects revealed as we gazed through different lenses or perhaps entered the room with different orientations. We did not attempt to correlate the two accounts because their premises are so very different, perhaps incommensurable. Instead of triangulation through different data points produced by the methods we used, we expect to end up with two separate accounts, with little to tie them together. Nonetheless, they are separate accounts and it might be possible to gain some insight from each, especially as we view them together.

This study was conducted in a Multicultural Psychotherapy course, a required class for second-year doctoral students in a graduate program in clinical psychology. All of the19 graduate students enrolled in the course participated in the study. A 3-hour class session was structured to spend 1 hour in the simulation, 1.5 hours in didactic debriefing with RG and .5 hour in affective processing with WS. For this study, students wrote journal responses in the week after the class session. Additionally, qualitative data was collected prior to the class session and after the class session. This study was approved by the George Fox University IRB and consent was obtained from each participant before the course began.

During the simulation phase, students were divided into teams of 3 persons and had one hour to complete the activities. Specifically, the students needed to get the signatures of 4 specific individuals in different buildings across the compact, Liberal Arts campus. Each student on the team was assigned one of three defined roles: i) mobility impaired student (i.e., student in a wheelchair) - who rolled through the scavenger hunt and was responsible for getting the required signatures; ii) Visually impaired student (i.e., student wore low-vision goggles) who walked through the scavenger hunt and could aid the student in the wheelchair only if requested; iii) recorder (i.e., observer) - who walked with the team through the scavenger hunt and recorded where challenges were encountered and how non-participating people on campus responded to team members (e.g. eye contact, tone of voice, affect, etc.).

The debriefing phase of the activity was done immediately after the simulation and began with students in each role reporting their experiences. $R G$ then presented his experiences as a person with a disability and answered questions from students. He shared personally about how his disability has affected his daily life and activity level. He discussed the hegemonic messages given to persons with a disability e.g., the implicit message to stay home because of the difficulty in getting to places because of problems with access, the difficulties friends experience while trying to overcome structural and architectural barriers on behalf of the person with disabilities, and the negative responses of people who do not understand specific challenges faced by people with disabilities. He shared about the paradox of seeing the person with a disability like everyone else and at the same time acknowledging the disability effects every aspect of that person. He shared personal experiences where he felt systematic discrimination because of his disability. Lastly, he discussed what students can do in their clinical practice to effectively provide services to persons with disabilities (e.g., taking histories differently, disabilities etiquette, awareness of the politics of disabilities, etc).

Finally, the students entered the reflection phase. This began when RG left the class and WS guided students in processing their affective responses. The reflection phase continued in the week following the class as 
students were asked to write a journal entry in which they reflected on their own emotional responses, attitudes, and insights during and following the exercise. Students turned these journals in to WS, the course instructor, with the expectation that he would comment on them and the entry completion would contribute to course grades.

\section{Results}

\section{Quantitative results}

Before and after the class session, students were asked to respond on a scale of 1-10 (1=completely unprepared, $5=$ adequately prepared, $10=$ exceptionally prepared) to the prompt How prepared are you to work with a client with disabilities? Because the data are ordinal and not scalar, we compared the modes of the beforeand-after responses and used a Wilcoxon Signed Ranks Test to compare the numbers of students who became more and less confident in their preparation following the class exercise. More complex quantitative measures, such as means, variances and standard deviations would not be appropriate for use with these data.

The modal response before class was 4 (range 3-7) while the modal response after class was 7 (range 2-8). A Wilcoxon test indicated that significantly more students reported increased confidence after the exercise $(n=10)$ than less confidence $(n=3)$ or no change $(n=4)$, $\mathrm{z}=1.99, \mathrm{P}=.047$. Interestingly, two students said they were more humble and aware that they would need to do more to feel competent to work effectively with people with disabilities. Their responses in the more conservative direction imply an even stronger effect of the intervention than is reported.

\section{Qualitative results}

All of the written responses of the students were collected and WS, KG and SH collaboratively selected quotations addressing the impact of the exercise on the students' professional preparation and personal development. There were no explicitly negative comments, and these three evaluators agreed on which quotations would be reported.

Before the Scavenger Hunt, two students acknowledged that they already had clinical work with people with disabilities. Interestingly, after the event more students referred to their previous clinical experiences. Prior to the exercise, students said their approach with clients with disabilities would be strengths-based and students said they would be direct in asking about the disability.

I think I would try to talk about the disability early on in our first session, and make sure I was not missing anything they would like me to know about that part of his or her life.
Most students acknowledged the need for flexibility of responses and the desire to accommodate the needs of the people with disabilities to host the therapy session well.

My answer varies significantly depending on the disability. However, as a general response, I would ensure my environment and therapeutic approach was appropriate for the client. I would want to gain specific knowledge regarding the disability to ensure I was aware of any accommodations I would need to make.

After the Scavenger Hunt, all the pre-exercise themes were echoed as well as deepened with additional details and some new insights. For example, students acknowledged that the person with a disability is not just their disability.

I would work to ensure the client felt seen for who they are as a person, not as their disability. I would be conscious of how directly their disability impacts who they are in the world but also attend to discovering how it is they desire to be seen.

Students expressed more concern about the client's subjectivity after the exercise.

I would realize that the client is not their disability, but their disability affects everything they do. I would ask my client about their disability, but it would not be the first question I would ask. I would try to get to know their interests. I would not make assumptions about their disability, no matter how much I thought I knew about what life was like for them. I would want to know about their subjective experience of their disability, how they feel about others...I would want to know about their isolation, their longing for connection, and the ways that the world moves with them.

Students also saw the potential need to advocate for and with their clients with disabilities after the exercise.

Working with an individual with a disability may require advocacy, as they often lack power in an environment that is unaccommodating to their needs.

I would become familiar with community resources that may help meet particular needs that the client brings into therapy, that cannot be dealt with inside of the therapy room.

After the exercise, a few students reflected pointedly about their own biases.

Softening my heart, becoming aware of my incredible fear of the other that comes through as anxiety...Realizing I subtly avoid situations where I do not know what to do socially...I avoid people with disabilities and people who are different from me because I get uncomfortable. I am ashamed of seeing this side of me, but seeing this side makes me think I am now only beginning to be prepared to work with people with disabilities.

After the Scavenger Hunt, students said that knowing 
non-clinical people with disabilities or knowing people with disabilities in non-clinical settings would be helpful. They added that examining their own biases would help them be better prepared.

...being friends with people with disabilities, taking time at church to talk with those who have disabilities and talk with them about their lives, not just focus on challenges but person as a whole, doing clinical work with people with disabilities, taking time to examine my own prejudices and macro-aggressions and assumptions that I may have when interacting with individuals with varying disability.

Finally, after the exercise, students added that the experience helped them feel more prepared and better able to anticipate asking questions and being flexible.

My hope that I would be able to avoid major mistakes and be able to determine what goals a person has, and how they are working towards them. I also feel like I have a little more knowledge into what life can look like. Learning about the difficulties with ADA accessibility, the contributing factors to loneliness, and the lack of unification within disability groups was helpful.

I feel more prepared now that I have had not just academic exposure but also had a specific experience with a person with a disability. Experiential learning imprints the person's story into memory with more meaning than strictly reading an academic text.

In the journals that students wrote the week after the Scavenger Hunt, their responses were deep and self-reflective. Two common themes were the value of the combined class experience (i.e., simulation and didactic debriefing) and the importance of RG's emotional vulnerability during his presentation. Students also described the value of the experience in preparing them to be better clinicians.

About a third of the students described a more transformational insight, usually by revealing a personal failure, e.g. bias, misperception and then committing to better preparation. One student wrote,

I have spent a lot of time with people with a lot of different problems, but not until this presentation did I realize how far removed I was and how far guarded I was from the lived experience of people with disabilities. I am afraid of dwelling in the sorrows and sufferings, even for a moment, that a disabled person experiences for many moments of every day. I am terrified of even trying to understand; there is so much sadness. I want to grow in my ability to be an ally to the disabled community. I want to recognize the paradox...

Another student said,

I wanted to leave class feeling like we are doing $O K$ as a society, not that we are leaving precious souls behind as we march on focused on fueling [our] own lives and meeting our own needs. As a therapist I want desperately to help all my clients, especially those with disabilities to find their place in the world where they can reach their potential and feel satisfied in being who they are called to be.

Finally, one student reflected on his own identity as a person with a disability in ways that he has not in other contexts.

However, the fact my disability has been largely treatable with medications makes me a privileged individual. Which leads me to return to my earlier statement that self-disclosure of any of my personal experiences with the disability culture needs to be done with great discernment. My treatable condition also gives me privilege in my role as a therapist in that I have experiences in the disability culture that other psychologists can never have. This equips me to work within the disabled community in ways that even a professional degree cannot.

\section{Discussion}

Critical theory claims that we are all, to some extent, products of our environment, society, history, and culture. Our taken-for-granted, mundane experiences contribute to our individual and collective worldviews, and these worldviews are active participants in the re-/creation of what the world means for each of us. These forces are powerful, especially as they are taken-forgranted and thus not typically subjected to examination and evaluation, sometimes powerful enough to cause us to work against our own self interests. ${ }^{15}$

Worldviews are not, however, fixed or unassailable. Through a process of education, of reflection and especially by utilizing way-points that are foreign to existing dominant paradigms, individuals may hold their attitudes and opinions up to examination thus subjecting them to the potential for change. This is not something that can be done for someone, however, and the whole process may well be resisted by the individual under examination. Such resistance may even lead to people actively striving to participate in their own deception or even their own oppression. ${ }^{16}$

Thus, there is no set syllabus for creating change within people. Each individual must find ways in which their existing worldview sits uneasily, where one element seems to work against another. By identifying and amplifying these incongruences, through a process of intense self-reflection, people can nurture the conditions necessary for change. It is the internal landscape, at least as much as the external, in which the primary rearrangement must occur. External, even societal and cultural changes, become more likely because they begin and are supported by the individual's new internal landscape, the new set of taken-for-granteds. These newly discovered beliefs and attitudes are even stronger than the ones that 
preceded them because they have arisen out of the process of self-reflection rather than of acceptance from an external authority.

Critical theory then would predict many of the findings of Shakespeare and Kleine (2015). An external lecturer would be unlikely to initiate fundamental change in the way students see themselves and others. Individual encounters with people with disabilities would be expected to provide more likelihood of attitude change, but unreinforced, these changes are unlikely to withstand the pressure of the many factors relentlessly promoting the previously held perspectives. Lasting attitude change would be the result of i) long term exposure to people whose experience contradicts the generally held world views, ii) experiencing a multitude of mundane, takenfor-granted experiences which lend their accumulated weight to the pressure to change existing beliefs, iii) coupled with a strong incentive to self-reflection through the diagnostic patient/provider relationship and its expectations. This combination would be predicted to be among the most effective routes to significant change of existing values about people with disabilities, and would be expected to be among the only techniques leading to long-term change in the way individuals see their worlds.

The four tasks we asked students to engage in were a simulation of disability and by themselves - isolated from the context of an unfolding worldview - would likely lead to distorted views of the experience of people with disabilities, for whom the disability is a taken-forgranted part of their worlds. An encounter with a person with disabilities alone may be emotively rich and an introduction into another's very different worldview but without the personal experience and devoid of the process of intense self-reflection of how these new perspectives may or may not fit among those previously held, the encounter alone is unlikely to result in real change in the way students live in their worlds. Journaling encourages self-reflection, but without the real world experiences and without sufficient friction among existing perspectives, the reflective exercise itself is unlikely to result in significant change once the student reinserts into their existing environment, which was largely responsible for creating their existing perspectives about people with disabilities.

Another way of perceiving this change incentive is to note the changed relationship between the investigator and investigated. In a lecture we get an account of someone else's inquiry about something. In a one-time encounter, we experience a taste of better understanding of the subject (i.e. persons with disabilities) through a new and more personal mode of examination. In the journaling process, we are pushed to look beyond the surface relationships of the things we see and ensure they fit within our existing way of seeing the world. Once we combine these approaches, however, a new transformation occurs.
Instead of the person with disabilities being the subject of the investigation by the researcher, or of an account of another researcher's journey, the subject of the investigation is the student and his or her own existing worldview, while the person with disabilities does not replace the student in role of researcher, but rather becomes a guide. Thus, when these three elements are combined - simulation, encounter, and reflection - the process transforms into one in which the student becomes the researcher and the subject being investigated is the student's own world view, his or her internal terrain.

As we delved deeper into the Shakespeare and Kleine data, we wondered whether a new category might make their model even stronger. In their analysis, there is no specific category for reflection and relevance, functions filled by our journaling process. It is easy to contemplate how the structured or semi-structured exercise of guided reflection over one's attitudes and experiences with people with disabilities might be more effective in achieving long-term results than any exercise in which the participants might stop consideration at the conclusion of the contact. One would expect that active and deep reflection would result in additional depth of change and perhaps even make the changes more resilient.

A reexamination of articles cited by Shakespeare and Kleine reveals that those in which attitude change did occur included some activity that required students to reflect on their experiences with persons with disabilities. The reflective activities took many forms. In some cases, like ours, students wrote journals or reflective responses. ${ }^{17-21}$ In other instances, reflection took place in the context of discussions. ${ }^{22-24}$ Importantly, instances in which there was no reflection, no attitude change (or negative change) was found, ${ }^{25,26}$ although knowledge change might occur. ${ }^{27,28}$

Finally, two programs were described and implemented, but no outcome data were reported. These are a program described by Symons, McGuigan, and Akl which asks students to journal and a recent description by Boyd of a program requiring reflective discussions. ${ }^{29,30}$ We anticipate that data from both of these programs will reveal attitude change toward people with disabilities.

\section{Limits, scope and further investigation}

Researchers and clinicians have acknowledged that merely assessing a phenomenon can serve as an intervention. Campbell and Stanley and Cook and Campbell describe the testing threat in quasi-experimental research designs. ${ }^{31,32}$ They ask whether the very experience of answering question, for example pre-intervention questions, might engage students in a way that poses a threat to the internal validity of a research design. In our exercise, the students knew they would be involved in some sort of research project about the course material before the simulation and it is not unreasonable to sug- 
gest that the pretesting primed students for the other phases of the experience.

The students' responses were also impacted by the strength of the intervention. Several aspects of pedagogy affected the intensity of the simulation. For example, over the years we have increased the length of time spent in the simulation. Also, we have conducted the simulation in some years switching among the team members, so that each had an opportunity to be sight-impacted, mobility-disabled, and the recorder. Our experience has been that the longer a student participates with the loss of vision, for example, the more poignant the experience and the greater the sense of loss. It takes a while for novelty to wear off, and even longer for adaptive changes in behavior to begin to take effect - such as the visually impaired student giving up on being part of the conversation because of the difficulty of following in the absence of visual conversation cues. Instructional time is always limited, and the time required to switch roles is also time deducted from the experience of conducting tasks, and thus time for the desired inversions to occur.

This exercise is also likely effective because we have crafted it for an appropriate audience. Graduate students who have been selected into and begun their training within a program of clinical psychology might be more open to empathic experiences, critical of their own existing biases and sensitive to the need for additional changes in their perceptions of others than even students in medical school..$^{33}$ At times we have adapted this exercise to an undergraduate classroom, with limited success. It did seem to open students' eyes to the awful obstacles faced by people with disabilities, although in some cases the sort of distortions talked about in Shakespeare and Kleine could be seen, leading to a false sense of adventure - almost like a real-life video game - as students basking in the novelty raced downhill in wheelchairs in the absence of serious real-world strictures against failure. In other cases students were overheard making statements such as, I don't see how anyone could ever get anything done like this hinting at a fatalism not helpful in preparing to assist people with disabilities. Journaling by undergraduate students also did not seem to result in the same depth of reflection and thus provided a limited opportunity for the transformative inversion graduate students experienced, although there clearly are studies that demonstrate journaling can be effective in changing undergraduate students' attitudes toward people with disabilities. ${ }^{34}$

Thus it is possible that the synergies experienced among the simulation, debriefing, and journaling components of this exercise, when transplanted to other disciplines, might not result in the life transforming changes we witnessed. It might be of particular interest to investigate responses among students arranged in different typologies. Another set of interesting questions for additional research involves the relative effectiveness of different presenters. RG has always been the presenter in this program, and while he holds a doctorate in the social sciences and humanities, he is not a professional clinical psychologist. Given our assumptions about the importance of the status of the presenter, might this be more or less effective than featuring someone with a disability who is a practicing clinician, professor, or other health care professional?

We also wondered how these changes might hold up over time. Our students continue to be immersed in a training program that values their ability to serve people with disabilities, however Wong and Wong observed, when students who have experience positive attitude change about people with disabilities are returned to an inhospitable environment their attitudes quickly revert back. ${ }^{35}$ As Iezzoni, Ramanan, and Drews comment, this is especially true when disrespectful attitudes about people with disabilities are modeled by more senior, and therefore more powerful, students, faculty, and supervisors. ${ }^{36}$

Perhaps the most important limitation of this work, as well as the single area crying out most fearfully for additional study, is the question of effectiveness and the predictive validity of our quantitative outcome measures. While we have taken some steps to address these concerns by examining our data in qualitative terms, much investigation remains into the complex ways in which students/professionals/society and cultural members form and interact and the ways perspectives are created and altered. The studies reviewed by Shakespeare and Kleine utilize a collection of qualitative and quantitative perspectives which offer some intuitive measures of effectiveness of knowledge and attitude changes, yet this begs the question as to whether greater sensitivity towards people with disabilities is in fact the climactic attitude, or whether a more realistic perspective would be to follow the long-term value of these interventions to see whether it impacts our students' future clinical practice and whether their clients can identify their attitudes as helpful and them as allies in the health care of people with disabilities. ${ }^{20,27}$ Even traditional concepts such as effective come embedded with specific cultural and social perspectives with biases, adopting positions which take for granted ill-defined social goals and unintended consequences. Who, for example, gets to determine just what is best for both clinicians and for clients? We expect that an increased attention to qualitative methods and research designs will provide enough richness and variety to begin the work of identifying consequences of rendering problematic unexamined popular culture perspectives about disabilities and the people who live with them.

In regards to the methods we used, we need to exercise some care. Our quantitative approaches make the huge assumption that respondents' use of words means the same as the researchers intended, and that each respondent's use of a similar response means the same as 
each other respondent. This assumption is given in the very process of counting things. We make similar assumptions, if not so sweeping, in our qualitative approach, We do, after all, presume a common understanding of the same word symbols so that we do understand what respondents meant by their choice of words. Ultimately these assumptions find support in the variety of journal responses, and the consistent tone. We must continue to remember that words are complex things, and that our construction of meaning is very much a joint endeavor between researchers and respondents One area for further study might be looking for other evidence that long term change did occur, beyond a change in vocabulary.

\section{Conclusions}

The purpose of this project was to evaluate the effectiveness of a pedagogical exercise in changing attitudes toward disability among graduate students preparing for careers in mental health professions. In the end, we are cautiously optimistic that changes in training health care providers, especially using simulation, debriefing, and guided self-reflection in combination can change attitudes and, thus, could positively impact the care of people with disabilities.

\section{References}

1. Sharby N, Martire K, Iversen MD. Decreasing health disparities for people with disabilities through improved communication strategies and awareness. Int $\mathrm{J}$ Environ Res Public Health 2015;12:3301-16.

2. Robey KL, Minihan PM, Long-Bellil LM, et al. Teaching health care students about disability within a cultural competency context. Disabil Health J 2013;6:271-9.

3. Brault MW. Americans with disabilities: 2010. In: Current population reports. Washington, DC: US Census Bureau: 2012. pp 70-131.

4. U.S. Department of Health and Human Services: healthy people 2020. Washington, DC: U.S. Dept. of Health and Human Services; 2014.

5. Olkin R. Could you hold the door for me? Including disability in diversity. Cultur Divers Ethnic Minor Psychol 2002; 8:130-7.

6. U.S. Office of the Surgeon General. Closing the gap: a national blueprint for improving the health of individuals with mental retardation. Report of the Surgeon General's Conference on Health Disparities and Mental Retardation. Washington, DC: U.S. Department of Health and Human Services; 2002.

7. Kirschner K, Curry RH. Educating health care professionals to care for patients with disabilities. J Am Med Assoc 2009;302:1334-5.

8. American Psychological Association. Guidelines for assessment of and intervention with persons with disabilities. Am Psychol 2012;67:43-62.

9. Vogel M, McMinn M, Peterson M, Gathercoal KA. Examining religion and spirituality as diversity training: a multi- dimensional look at training in the American Psychological Association. Prof Psychol Res 2013;44:158-67.

10. Olkin R, Pledger C. Can disability studies and psychology join hands? Am Psychol 2003;58:296-304.

11. Rosa NM, Bogart KR, Bonnett AK, et al. Teaching about disability in psychology: an analysis of disability curricula in US undergraduate psychology programs. Teach Psychol 2016;43:59-62.

12. Andrews EE, Lund EM. Disability in psychology training: where are we? Train Educ Prof Psychol 2015;9:210-6.

13. Shakespeare T, Kleine I. Educating health professionals about disability: a review of interventions. Health Soc Care Educ 2013;2:20-37.

14. Friesen N. Critical theory: ideology critique and the myths of e-learning. Available from: http://ubiquity.acm.org/article.cfm?id $=1386860$

15. Habermas J. Theory of communicative action, volume two: lifeworld and system: a critique of functionalist reason. Boston, MA: Beacon Press; 1987.

16. Gramsci A. Selections from the prison notebooks. New York, NY: International Publishers; 1971.

17. Amosun SL, Volmink L, Rosin R. Perceived images of disability - the reflections of two undergraduate medical students in a university in South Africa on life in a wheelchair. Disabil Rehabil 2005;27:961-6.

18. Berg AL, Canellas M, Salbod S, Velayo R. Exposure to disability and hearing loss narratives in undergraduate audiology curriculum. Am J Audiol 2008;17:123-8.

19. Block P, Ricafrente-Biazon M, Russo A, et al. Introducing disability studies to occupational therapy students. Am J Occup Ther 2005;59:554-60.

20. Corwin SJ, Frahm K, Ochs LA, et al. Medical student and senior participants' perceptions of a mentoring program designed to enhance geriatric medical education. Gerontol Geriatr Educ 2006:26:47-65.

21. Gitlow L, Flecky K. Integrating disability studies concepts into occupational therapy education using service learning. Am J Occup Ther 2005;59:546-53.

22. Anderson ES, Smith R, Thorpe LN. Learning from lives together: medical and social work students' experiences of learning from people with disabilities in the community. Health Soc Care Commun 2010;18:229-40.

23. Duggan A, Bradshaw YS, Carroll SE, et al. What can I learn from this interaction? A qualitative analysis of medical student self-reflection and learning in a standardized patient exercise about disability. J Health Commun 2009;14:797-811.

24. Moroz A, Gonzalez-Ramos G, Festinger T, et al. Immediate and follow-up effects of a brief disability curriculum on disability knowledge and attitudes of PM\&R residents: a comparison group trial. Med Teach 2010;32:e360-4.

25. Fruhauf CA, Jarrott SE, Lambert-Shute JJ. Service-learners at dementia care programs: an intervention for improving contact, comfort, and attitudes. Gerontol Geriatr Educ 2004;25:37-52.

26. McConville SA, Lane AM. Using on-line video clips to enhance self-efficacy toward dealing with difficult situations among nursing students. Nurse Educ Today 2006;26:200-8.

27. Kleinert HL, Sanders C, Mink J, et al. Improving student dentist competencies and perception of difficulty in delivering care to children with developmental disabilities using a virtual patient module. J Dent Educ 2007;71:279-86.

28. Zwahlen D, Herman CJ, Smithpeter MV, et al. Medical students' longitudinal and cross-sectional attitudes toward and 
knowledge of geriatrics at the University of New Mexico School of Medicine. J Am Geriatr Soc 2010;58:2049-50.

29. Boyd K. The curriculum of caring: Fostering compassionate, person-centered health care. AMA J Ethics 2016;18:384-92.

30. Symons AB, McGuigan D, Akl EA. A curriculum to teach medical students to care for people with disabilities: development and initial implementation. BMC Med Educ 2009;9:78.

31. Campbell DT, Stanley JC. Experimental and quasi-experimental designs for research. Boston, MA: Houghton Mifflin Company; 1966.

32. Cook TD, Campbell DT. Quasi-experimentation: design and analysis issues for field settings. Chicago, IL: Rand-McNally; 1979.

33. Sherrard S. Empathy in psychology and medical students: an investigation of the cognitive and emotional components of empathy. Newberg, OR: George Fox University; 2007.

34. Lower E, Dreidger D. Before and after, self inventory, and self reflection. Available from: http://dsq-sds.org/article/ view/141/141

35. Wong PKS, Wong DFK. Enhancing staff attitudes, knowledge and skills in supporting the self-determination of adults with intellectual disability in residential settings in Hong Kong: a pretest-posttest comparison group design. J Intellect Disabil Res 2008;52:230-43.

36. Iezzoni LI, Ramanan RA, Drews RE. Teaching medical students about communicating with patients who have sensory or physical disabilities. Available from: http:/www.dsqsds.org/article/view/527/704 